\title{
INVESTIGATION OF THE DRYING PROCESS WITH LOW HEATED AIR IN THICK LAYER OF GRAIN
}

\author{
Janis Palabinskis, Aivars Aboltins \\ Latvia University of Life Sciences and Technologies, Latvia \\ janis.palabinskis@1lu.lv, aivars.aboltins@1lu.lv
}

\begin{abstract}
The aim of the study is to find out the changes of grain moisture and temperature when drying with $20^{\circ} \mathrm{C}, 30{ }^{\circ} \mathrm{C}$ and $40{ }^{\circ} \mathrm{C}$ warm air. The average initial moisture of the grains ranged from $26 \%$ and they were dried to $14.6 \%$. The grain layer was divided into five elementary layers (containers) with a total layer thickness of 165 $\mathrm{mm}$. When dried at $40^{\circ} \mathrm{C}$, the grain reached the optimum moisture content in 4 hours and 30 minutes, but when using unheated air, this process took about 3 times longer. When drying at $40{ }^{\circ} \mathrm{C}$, drying takes place gradually over all 5 grain layers. In containers 1 and 2, drying from the air inlet side is better from the beginning, but as the process takes longer, the grain becomes drier and the moisture output in these containers starts to decrease. When using $30^{\circ} \mathrm{C}$ warm air, drying for up to 2 hours practically takes place only in containers 1 and 2 , but after 2 hours the moisture output already starts to increase in the drying container 3 . In turn, in containers 4 and 5 , the moisture output is very low throughout the experiment, and after drying for 4 hours and 30 minutes, the moisture output in container 4 is 2.7 grams and in container 52.1 grams per 100 grams. The results of the study showed that moisture removal from grain occurs most rapidly in the lower layer. When dried with $20^{\circ} \mathrm{C}$ warm air for 4 hours and 30 minutes, moisture removal takes place only in containers 1 and 2, but after 3 hours, container 3 also begins to remove moisture. Containers 4 and 5 practically do not return moisture, at the end of the experiment only 1.98 grams were removed from container 4 and 1.85 grams per 100 grams from container 5.
\end{abstract}

Keywords: drying process, wheat, air, low-heated.

\section{Introduction}

The drying of foods and crops is a major operation in the food industry, consuming large quantities of energy. Drying operations alone account for $10 \%$ to $25 \%$ of the total energy in the food processing industry worldwide [1]. Drying accounted for about $10-15 \%$ of all industrial energy consumption in Canada, France and 20-25\% in Germany and Denmark [2].

Therefore, as in other energy-intensive industries, it is important to look for energy-saving strategies and technologies in order to achieve the most efficient economic regime in the drying industry.

One of the main goals in designing and optimizing industrial drying processes is to reduce moisture at minimum costs. Presently, climate energy conservation plays a major role to make the process sustainable, to design a more efficient process, energy use and quality changes, as well as heat and mass transfer during drying.

Grain drying by hot air convection consists of moist grains and hot air, which is a multi-component and multi-phase system. Mass migration in this system can be considered as a one-component water migration, but a certain amount of energy migration must also be included, and the endpoint is the grain moisture balance [3]

In developing efficient energy-saving drying methods, many scientists have theoretically analyzed energy transfer mechanisms such as dryer energy consumption, exergy, energy loss, and energy conversion efficiency $[4 ; 5]$ and have studied the energy and material consumption of drying systems and the law of heat mass transfer of different dried materials, which were tested experimentally [6-8].

Electricity is a clean, efficient, convenient, easily controllable and convertible form of energy, as the process of drying grain seeks clean heat sources and reduces pollutant emissions. Today, it is important to measure and develop low carbon, save energy, and protect the environment, use friendly grain dryers and explore electric grain dryers that use electrical energy as a heat source.

Grain dryers with exhaust gas drying and the use of phase change latent heat from steam condensation during drying significantly reduce the energy consumption of the dryer [9].

There have been many achievements over the last decade technologies and methods have emerged with the aim of reducing various quality degradation food attributes during drying. Therefore, careful selection of drying techniques and optimizing drying conditions play an important role. Physical changes (e.g., the shape and size, as well as changes in color and microstructure) change consumer decisions during buying products $[10 ; 11]$. 
Drying with slightly heated air is becoming more and more important. Its greatest benefit is the preservation of the original biological value of the product. To make a better and more rational use of energy for drying products, it is necessary to experimentally study the process itself. Many researchers use the thin layer draying model for determination of the drying process. Some researchers directly focused on wheat drying [12-17].

Our goal was to study the forced drying process of wheat grain in different thicknesses of its layer at different air temperatures.

\section{Materials and methods}

For experimental studies a sieve dryer model was used for drying summer wheat grain in layers (Fig. 1). For active ventilation a Europlast EXTRA d100 mm fan (1) with a power of $19 \mathrm{~W}$ and an air flow capacity of $100 \mathrm{~m} 3 / \mathrm{h}$ was built into the model. To stabilize the air flow between the fan and the ventilated grain a $500 \mathrm{~mm}$ high pipe is located (2). Above the pipe there are placed $220 \mathrm{~mm}$ diameter 5 grain sieves containing the material to be dried (3).

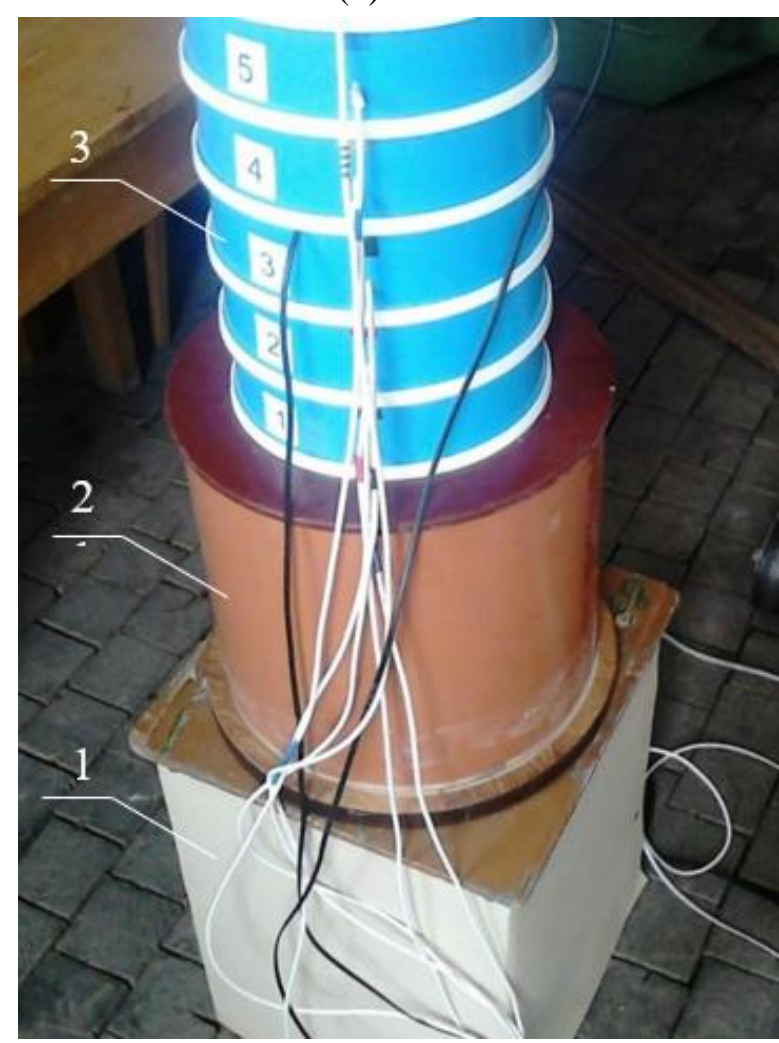

Fig. 1. Experimental sieve dryer model

An air heater Philips HD 3269/A (230 V/50 Hz, $2000 \mathrm{~W})$ was used to heat the ventilated air, which will ensure the temperature of the air used for drying. Electronic scales KERN EW1500 2M (Max $1500 \mathrm{~g}$, min $0.5 \mathrm{~g}, e=0.1 \mathrm{~g}, d=0.01 \mathrm{~g}, \mathrm{DC} 9 \mathrm{~V}$ ) were used for weighing grain. A Supertech measuring device was used to determine grain moisture.

A KM 120 logger developed by "Mītavas robots" was used to read and store temperature and humidity measurements. A temperature sensor was installed in each sieve and air temperature and humidity sensors were additionally installed in sieves 3 and 5 .

Drying was performed at 3 different temperatures: $20^{\circ} \mathrm{C}, 30^{\circ} \mathrm{C}$ and $40{ }^{\circ} \mathrm{C}$. The duration of the experiment was 4 hours and 30 minutes, during which the moisture content of the grain was measured before and at the end of drying. The initial moisture content of the grain ranged from $28 \pm 1 \%$, and the grains were dried to $14.6 \%$. The total layer thickness was $165 \mathrm{~mm}$. The ambient temperature was $21^{\circ} \mathrm{C}$.

At the beginning of the study the grain was weighed every 20 minutes to obtain results, later increasing the interval between weighing time intervals. 


\section{Results and discusions}

When dried at $40{ }^{\circ} \mathrm{C}$, the grain reached the optimum moisture content in 4 hours and 30 minutes, but when using unheated air $\left(20^{\circ} \mathrm{C}\right)$, this process took about 3 times longer. The moisture content of the grain after drying for 4 hours and 30 minutes can be seen in Fig. 2.

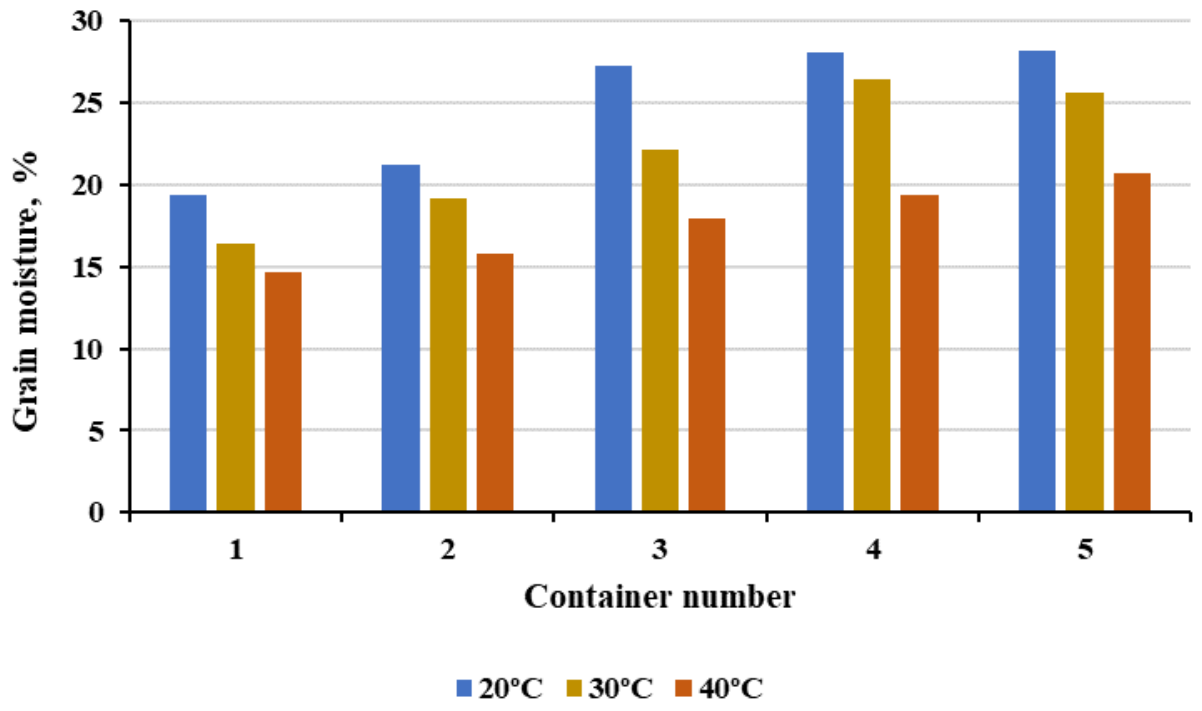

Fig. 2. Grain moisture after $4 \mathrm{~h} 30 \mathrm{~min}$ drying at different drying temperatures

When drying with $40^{\circ} \mathrm{C}$ warm air, drying occurred gradually over all 5 grain layers. At the beginning of the drying process, the moisture output in containers 1 and 2 is higher, but as the process becomes longer and the grain becomes drier, the moisture output in these containers starts to decrease (Fig. 3). The moisture removal in the 3rd vessel is even throughout the experiment and does not change during the experiment. In turn, in containers 4 and 5, the moisture output at the beginning of the experiment is minimal, but as the duration of the experiment increases, it begins to increase.

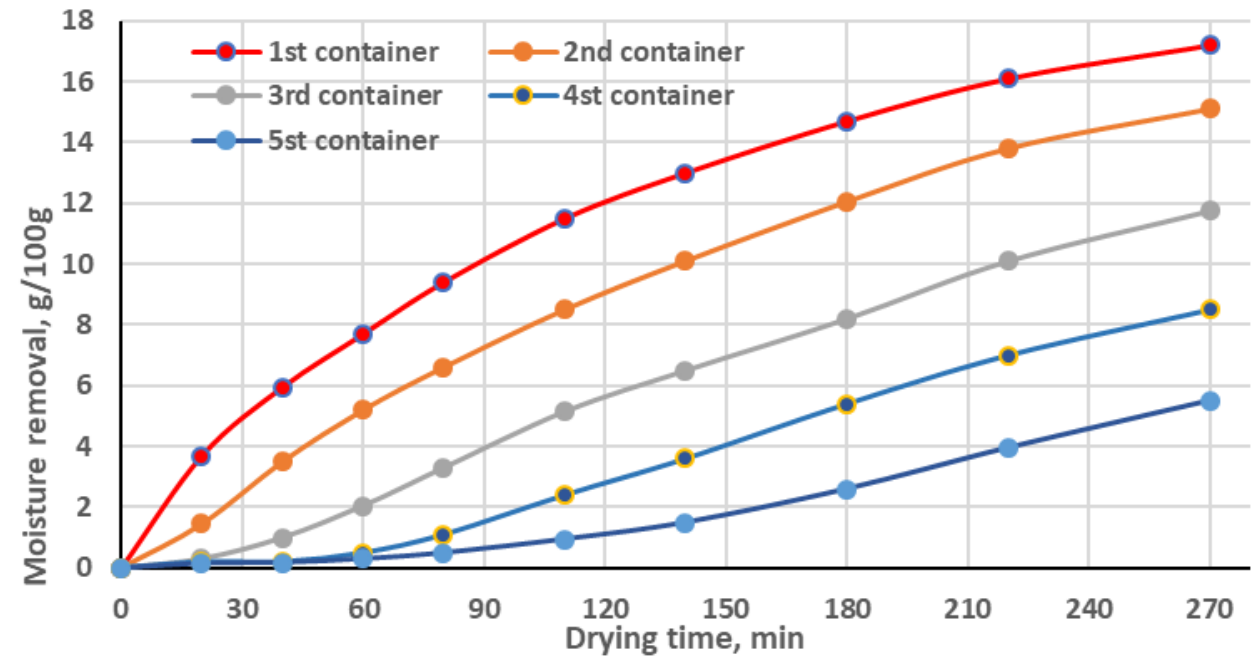

Fig. 3. Moisture removal in layers by drying with $40^{\circ} \mathrm{C}$ warm air

The temperature in the $3 \mathrm{rd}$ grain layer for 1 hour 40 min was $20 \pm 1^{\circ} \mathrm{C}$ only after that it started to increase linearly to $35^{\circ} \mathrm{C}$ at the end of the process. In turn, the temperature of the upper layer remained at $20 \pm 1{ }^{\circ} \mathrm{C}$ for up to 3 hours and reached $25^{\circ} \mathrm{C}$ at the end of the process, although the layer was dried with $40{ }^{\circ} \mathrm{C}$ warm air. It should be noted that at the beginning of the process, the temperature of the drying agent in the grain layer dropped very rapidly. This can be explained by the fact that the grain had to be heated first and then the heat energy was used to evaporate the water.

The humidity of the heated air used for drying was close to $10 \%$, but in the outlet air above 5th grain layer in the first 3 hours it was $87-89 \%$. Around 100 minutes of drying, a sharp decrease in 
humidity and an increase in temperature between layers 3 and 4 were observed. Humidity above the 5th grain layer begins to decrease only after 4 hours and 30 minutes.

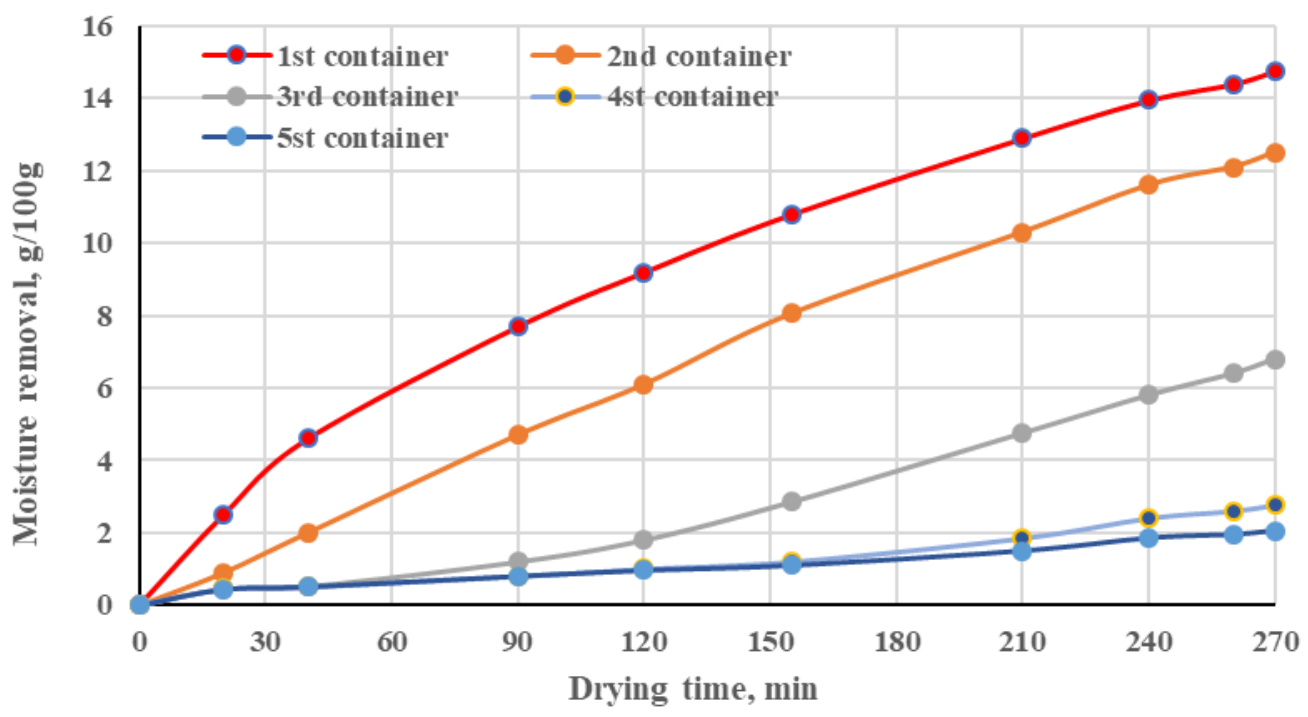

Fig. 4. Moisture removal by drying with warm air at $30{ }^{\circ} \mathrm{C}$

A drying study was performed with air heated to $30{ }^{\circ} \mathrm{C}$. The initial moisture content of the grain before drying in each container was $28.0 \%$. When using $30^{\circ} \mathrm{C}$ heated air, drying for up to 2 hours practically occurs only in containers 1 and 2, but after 2 hours moisture removal is also observed in the drying container 3 . In contrast, the moisture output in containers 4 and 5 is very low throughout the experiment, and after drying for 4 hours and 30 minutes, the moisture output in container 4 is 2.7 grams and in container $5-2.1$ grams per 100 grams (Fig. 4).

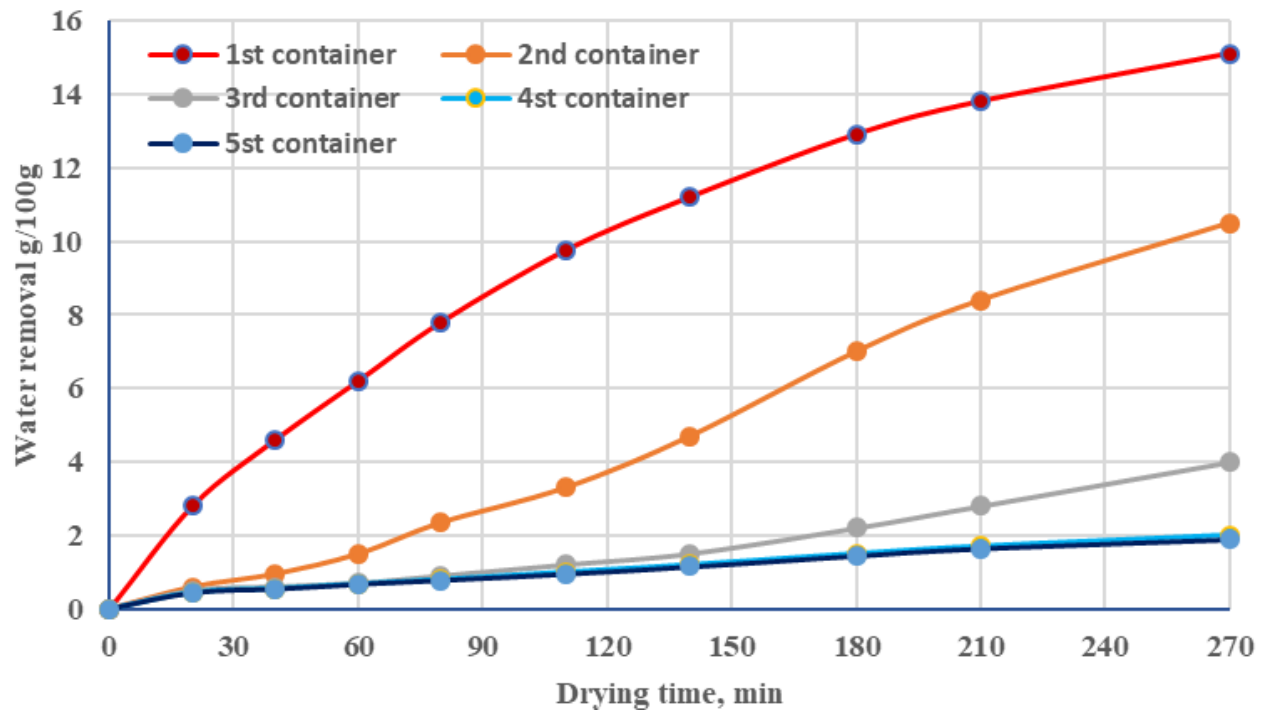

Fig. 5. Moisture removal using unheated air $\left(20^{\circ} \mathrm{C}\right)$

After drying with ambient air $\left(20^{\circ} \mathrm{C}\right)$ for 4 hours and 30 minutes, moisture removal occurred only in containers 1 and 2, but after 3 hours, container 3 also begins to remove moisture. Containers 4 and 5 practically do not return moisture, at the end of the experiment only 1.98 grams were removed from container 4 and 1.85 grams per 100 grams from container 5 (Fig. 5).

When dried with unheated air at $20^{\circ} \mathrm{C}$, it can be observed that the inlet air temperature is about $20{ }^{\circ} \mathrm{C}$ and the air humidity is about $30 \%$. Temperature in the middle layer (between layers 3 and 4 ) are lower than above layer 5 and no significant changes were observed throughout the study. Humidity did not change during this time and was around $92 \%$. 
After drying for 14 hours with $20^{\circ} \mathrm{C}$ warm air, the humidity at the end of the experiment was: 1 . in the first container $-14.6 \%$, in the second container $-15.4 \%$, in the third container $-17.1 \%$, in the fourth container $-19.4 \%$ and in the fifth container $-21,2 \%$. Moisture output per $100 \mathrm{~g}$ of drying material is shown in Fig.6.

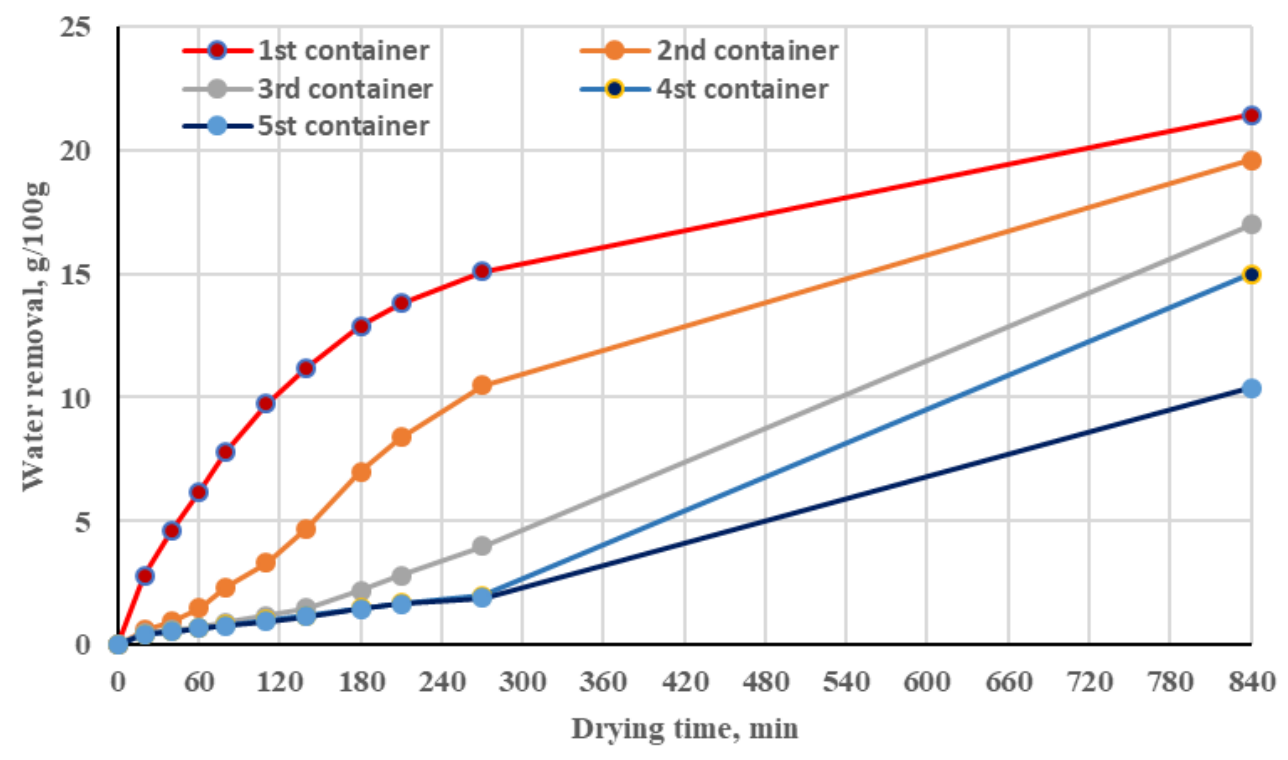

Fig. 6. Moisture removal by drying with unheated air to the humidity of condition

Continuing overnight drying, it was found that the air temperature between layers 3 and 4 reached room temperature $\left(17^{\circ} \mathrm{C}\right)$ and humidity of $53 \%$ during the ninth drying hour (Fig. 11). In contrast, the air temperature and humidity in the upper layer only start to change after 11 hours of drying, reaching a temperature of $14{ }^{\circ} \mathrm{C}$ and a humidity of $70 \%$ in the morning. The temperature in grain containers 1 and 2 even exceeds the inlet air temperature at the end of the drying process. In container 3 , the grain temperature is also close to the inlet air temperature, but in grain containers 4 and 5, it gradually increases towards the inlet air temperature.

\section{Conclusions}

1. Studies have shown that with active ventilation cereal grain with a moisture content of $26 \%$ to $14.6 \%$ can be dried in an unheated atmosphere air at $20^{\circ} \mathrm{C}$, but this requires about 3 times more time and energy compared to up to $40^{\circ} \mathrm{C}$ heated ventilating air.

2. When the grain is ventilated with $20^{\circ} \mathrm{C}$ warm air (relative air humidity $30 \%$ ) for 4.5 hours, the grain drying process takes place only in grain containers 1 and 2, but after another 3 hours the drying process also starts in container 3. At the same time, after 7.5 hours the beginning of the drying process was not detected in grain containers 4 and 5 .

3. Using $30{ }^{\circ} \mathrm{C}$ warm air, in 2 hours practically a decrease of grain moisture was observed only in containers 1 and 2, but after 2 hours moisture is removed from the third grain container.

4. Using ventilating air heated to $40^{\circ} \mathrm{C}$, the drying process takes place gradually in all 5 grain layers (containers).

\section{References}

[1] Mujumdar A. S., Passos M. L. Innovation in drying technologies. Drying Technology in Agriculture and Food Sciences. (Ed. A. S. Mujumdar) Enfield: Science Publishers Inc.,2000, pp. 291-310.

[2] Tohidi M., Sadeghi M; Torki-Harchegani M. Energy and quality aspects for fixed deep bed drying of paddy. Renew. Sustain. Energy Rev. 2017, 70, pp. 519-528.

[3] Li C. Y., Ma X. Z., Fang Z. D., Zhang. Y. Thermal energy structure of grain hot air drying and analytical method. Transactions of the Chinese Society Agricultural Engineering, 30(9), 2014, pp. 220-228. DOI: 10.3969/j.issn.1002-6819.2014.09.027

[4] Jing W. H., Jia Z. H., Luo W. Definition, calculation and application of total water potential. Transactions of the Chinese Society Agricultural Engineering, 24(2),2008, pp. 27-32 
[5] Li C. Y. Theoretical analysis of exergy transfer and conversion in grain drying process. Transactions of the Chinese Society Agricultural Engineering, 34(19), 2018, pp.1-8.

[6] Kic P., Aboltins A. Drying process of two special plants, Engineering for Rural Development 2014, 13, pp. 137-142

[7] Aboltins A., Kic P. Research in some medical plant drying process, Engineering for Rural Development 2016, pp. 1145-1150

[8] Aboltins A., Palabinskis J. Studies of vegetable drying process in infrared film dryer, Agronomy Research 15(Special Issue 2), 2017, pp. 1259-1266

[9] Wang G, Wu W, Qiao F, Fu D, Liu Z, Han F. Research on an electric energy-saving grain drying system with internal circulation of the drying medium. J Food Process Engineering 2020, v43 (9) pp.1-13 DOI: $10.1111 /$ jfpe. 13476

[10] Rubina T., Aboltins A., Palabinskis J. Drying characteristics of rhubarb cubes at low temperature Engineering for Rural Development , 2019, 18, pp. 1249-1256

[11] Aboltins A., Rubina T., Palabinskis J. Shrinkage effect on diffusion coefficient during carrot drying // Agronomy Research. Vol.16 (Special Issue 2) (2018), pp. 1301-1311.

[12] Wilcke W., Hellevang K. Wheat and Barley drying AG-FS-5949-A, 1992 Univ. of Minnasota. 2p.

[13] Hefni M., Witthoft C. M. Effect of germination and subsequent oven-drying on folate content in different wheat and rue cultivars, Journal of Cereal Science, 56, 2012, p. 374-378

[14] Sun Y., Guo X., Xu B., Wang C., Wang Y., Jiao Y., Li S., Ying J., Liu X. Design and test of a novel wheat drying oven based on the real-time utilization of diesel engine waste heat, Cogent Engineering ,2019, 6, 10 p. DOI: 10.1080/23311916.2019.1673118

[15] Mohapatra D., Spinivasa Rao P. A thin layer drying model of parboiled wheat, Journal of Food Engineering 66, 2005, pp. 513-518

[16] Nizamani M, Nizamani F.G, Nizamani A., L., Buriro M., Khokhar A., A., Rind R., A., Nizaman M.M. Effect of Drying Methods and Storage Periods on Wheat (Triticum aestivum L.) Quality Parameters, Indian Journal of Science and Technology, 2019, Vol 12(12), DOI: $10.17485 / \mathrm{ijs} / 2019 / \mathrm{v} 12 \mathrm{i} 12 / 141812$,

[17] Chan S., Kuo M. Wheat Germ Drying with Different Time-Temperature Combinations in a Fluidized Bed Dryer Processes 2018, 6, 24517 p.; doi:10.3390/pr6120245 